\title{
Effect of Interval Aging Mode on IMC Growth between Low Ag Content Sn-0.3Ag-0.7Cu-0.5Bi-Ni and Cu Substrate
}

\author{
Min QU, Yan CUI, Fengbin LIU, Zhiwei JIAO, Yuan LIU, Jun CHENG \\ School of Mechanical and Materials Engineering, \\ North China University of Technology, \\ Beijing, China \\ e-mail: minqu@ncut.edu.cn, cuiyan@ncut.edu.cn, fbliu@ncut.edu.cn, \\ zwjjzw@ncut.edu.cn, liuyuan@ncut.edu.cn,2935684@qq.com
}

\begin{abstract}
To simulate the application environment of a number of electronic products, the growth of $\mathrm{Sn-0.3Ag-0.7Cu-0.5Bi-Ni/Cu}$ solder joints with low content of Ag was investigated during aging in an interval mode. It shows that the intermetallic compound (IMC) $(\mathrm{Cu}, \mathrm{Ni})_{6} \mathrm{Sn}_{5}$ layer becomes thicker with increasing aging time. The growth of IMC $(\mathrm{Cu}, \mathrm{Ni})_{6} \mathrm{Sn}_{5}$ layer during aging follows the diffusion control mechanism. Furthermore, it is demonstrated that there is no IMC Cu3Sn layer appear whatever increasing the aging time. It is explained the phenomenon is mainly attribute to the interval aging mode. According to kinetics, the activation energy is not high enough to overcome the energy obstacle due to the interval aging mode and finally the Cu3Sn phase doesn't form. Hence, the reliability of solder joints is improved.
\end{abstract}

Keywords-Sn-0.3Ag-0.7Cu-0.5Bi-Ni solder; intermetallic compound; interval aging; thickness

\section{INTRODUCTION}

Due to the toxicity and environmental regulations, $\mathrm{Sn}-\mathrm{Pb}$ solders has been replaced with the lead-free solders in electronic industry ${ }^{[1]}$. Hence, a number of lead-free solders have been developed as the candidate solders ${ }^{[2-4]}$. Meanwhile, many lead-free solder alloys, mainly consist of Sn matrix and small additions of other elements, including $\mathrm{Sn}-\mathrm{Zn}^{[5]}$, $\mathrm{Sn}_{-} \mathrm{Sb}^{[6]}, \mathrm{Sn}-\mathrm{Cu}^{[7]}$ and $\mathrm{Sn}-\mathrm{Ag}$ alloys ${ }^{[8-10]}$, have received more attention. In fact, full implementation of new $\mathrm{Pb}$-free solders implies a detailed knowledge and understanding of their thermodynamics, wettability, microstructure, and so on. $\mathrm{Ji}^{[11]}$ studied $\mathrm{Sn}-0.7 \mathrm{Cu}$ solder alloy by pressureless and fluxless ultrasonicassisted die bonding, they observed that the joint consisted of sole $(\mathrm{Cu}, \mathrm{Ni}) 6 \mathrm{Sn} 5$ plus a thin layer of $\mathrm{Cu} 3 \mathrm{Sn}$, and compared with transient-liquid-phase soldering, this method dramatically reduces the processing time and there was no external force acted on the dies.

However, due to the disadvantages of the binary alloy, they are hard to match the properties of $\mathrm{Sn}-\mathrm{Pb}$ alloy. For example, their wettabilities are poorer than that of $\mathrm{Sn}-\mathrm{Pb}$ alloy, the melting points are higher than that of $\mathrm{Sn}-\mathrm{Pb}$ alloy. Hence, the ternary solder alloy are developed, they are mainly developed from Sn-Ag alloys system owing to the excellent mechanical properties. Among Sn-Ag-Zn, $\mathrm{Sn}-\mathrm{Ag}-\mathrm{Bi}$, and $\mathrm{Sn}-\mathrm{Ag}-\mathrm{Cu}$ alloys, $\mathrm{Sn}-\mathrm{Ag}-\mathrm{Cu}$ alloy has attracted most attention owing to their excellent mechanical properties and wettability[12]. Therefore, it has ever been the most promising solder alloy. Unfortunately, due to their high cost, the pervasive application of $\mathrm{Sn}-\mathrm{Ag}-\mathrm{Cu}$ alloy is hindered. Consequently, a new target about solders is appeared, which is to explore a $\mathrm{Sn}-\mathrm{Ag}-\mathrm{Cu}$ solder with low content of $\mathrm{Ag}$. Thus, the aim of the paper is to develop a new solder alloy.

Considering the high cost of $\mathrm{Sn}-\mathrm{Ag}-\mathrm{Cu}$ solder, some other alloying elements to lower the cost should be added, moreover, based on the low cost of the solder, it would be better keep the excellent properties of the solder. As Bi element can reduce the surface tension and then improve the solder wettability, thus, Bi was added into the $\mathrm{Sn}-\mathrm{Ag}-\mathrm{Cu}$ solder. However, Bi can reduce the ductility, considering $\mathrm{Ni}$ element can improve the creep property and toughness, Ni element was added into the solder further.

As a number of electronic products don't serve continuously, there could be some differences from the growth behavior of IMCs in different aging modes. In order to investigate the growth of IMCs in the real application environment, we adopt the interval aging mode. Thus, the aim of the paper is to research the growth character of $\mathrm{Sn}-0.3 \mathrm{Ag}-0.7 \mathrm{Cu}-0.5 \mathrm{Bi}-\mathrm{Ni} / \mathrm{Cu}$ solder joints with low $\mathrm{Ag}$ content during aging.

\section{EXPERIMENTAL PROCEDURES}

The commercial copper plates with dimensions of 15 $\mathrm{mm} \times 15 \mathrm{~mm} \times 3 \mathrm{~mm}$ were used as the substrates in this study. The copper substrates were ground with silicon carbide paper and polished with $0.25 \mu \mathrm{m}$ diamond paste until a mirror surface was obtained. The prepared substrates were then dipped into $50 \%$ (by volume) nitric acid $\left(\mathrm{HNO}_{3}\right)$ to remove oxide layer. $\mathrm{Sn}-0.3 \mathrm{Ag}-0.7 \mathrm{Cu}-0.5 \mathrm{Bi}-\mathrm{Ni}$ solder paste was then placed on the substrates with a diameter of $5 \mathrm{~mm}$ as shown in Fig.1. Further, solder joints were formed with a F4N infrared reflow furnace. The specimens were reflowed at above liquidus temperature but the peak temperature wasn't beyond $260^{\circ} \mathrm{C}$ for 250 s.

After reflowing, the prepared solder joints were performed isothermal aging experiment in an vacuum drying oven at $150^{\circ} \mathrm{C}$ for 2 days, 4 days, 6 days, 8 days and 10days, respectively. Most importantly, the interval aging was adopted in our study, namely, the solder joints were aged continuously for 17 hours and then stopped aging for 7 hours, then the operation was repeat until the total time reached $48 \mathrm{~h}$, $96 \mathrm{~h}, 144 \mathrm{~h}, 192 \mathrm{~h}$, and $240 \mathrm{~h}$, respectively. Considering a number of electronic products are not worked continuously during one day, we adopt the interval aging style to simulate 
the real application environment, so as to find the proper solder.

In order to investigate the formation and evolution of interfacial IMCs, specimens were sectioned perpendicularly to the solder/copper interface of the solder joint and mounted in Klarmount. They were successively ground down to 400 , 800, and 1000 grit using silicon carbide paper cooled with flowing water, and polished with $5 \mu \mathrm{m} \mathrm{Al} \mathrm{Al}_{3}$ suspension followed by $0.25 \mu \mathrm{m}$ diamond paste. The interfacial morphologies of solder joints were observed by a Scanning Electron Microscope (SEM, ZEISS-EVO18) equipped with an Energy Dispersive X-ray Spectrometer (EDS).

Considering the reliable and repeatable data of the mean thickness of IMCs layer, three solder joint samples for each reflow cycle and aging time were used, SEM image analysis software was then employed to digitally measure the areas of each sample's IMCs layers from left side to right side. The thickness of IMCs layer is determined by the area of the IMCs layer dividing its length, and the mean thickness of IMCs layers was then calculated by averaging the data.
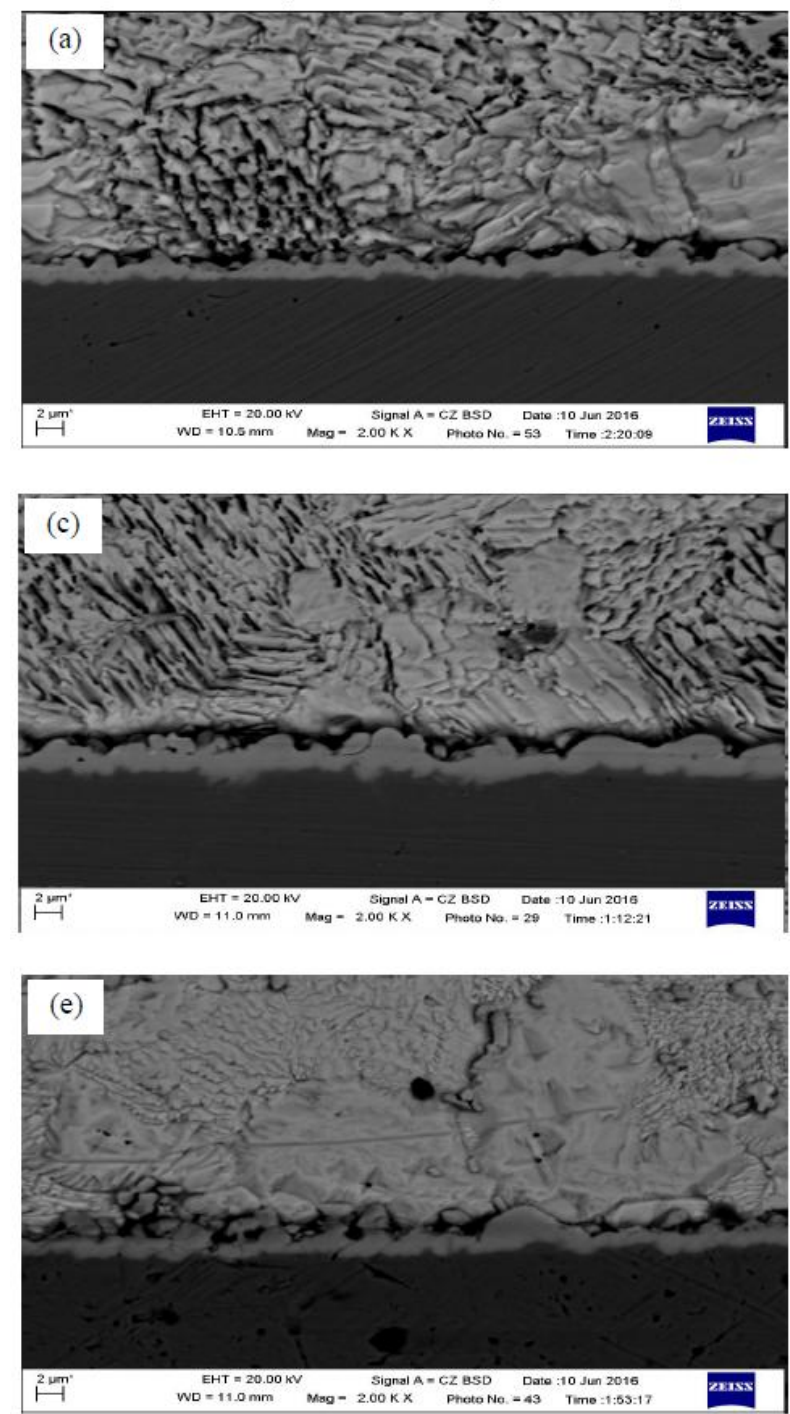

\section{RESULTS AND DISCUSSION}

The backscattered electron microscope images in Fig.1(a-e) show the interfacial microstructures of $\mathrm{Sn}-0.3 \mathrm{Ag}-0.7 \mathrm{Cu}-0.5 \mathrm{Bi}-\mathrm{Ni} / \mathrm{Cu}$ joints aging at $150^{\circ} \mathrm{C}$ for 2,4 , $6,8,10$ days, respectively. It is clearly seen that a narrow layer between the $\mathrm{Sn}$ matrix and $\mathrm{Cu}$ substrate in Fig.1(a-e), which is the intermetallic compound(IMC) layer. As well known, IMC layer is the key point to the reliability of solder joints, because the solder joints would fail if the IMC layer grows faster. The thickness of interfacial IMC layer increases with aging time. It is worth noting that only one IMC layer formed in solder joint with time aging, and the grain layer is $(\mathrm{Cu}, \mathrm{Ni})_{6} \mathrm{Sn}_{5}$. However, usually, the IMCs layer compose two layers, and a stable layer which is $\mathrm{Cu}_{3} \mathrm{Sn}$ is between $\mathrm{Cu}$ substrate and $\left(\mathrm{Cu}, \mathrm{Ni}_{6}\right)_{6} \mathrm{Sn}_{5}$ layer, but, the $\mathrm{Cu}_{3} \mathrm{Sn}$ doesn't appear in the experiment. The result is very similar to other solder system in our latest experiment, and it will be reported soon.
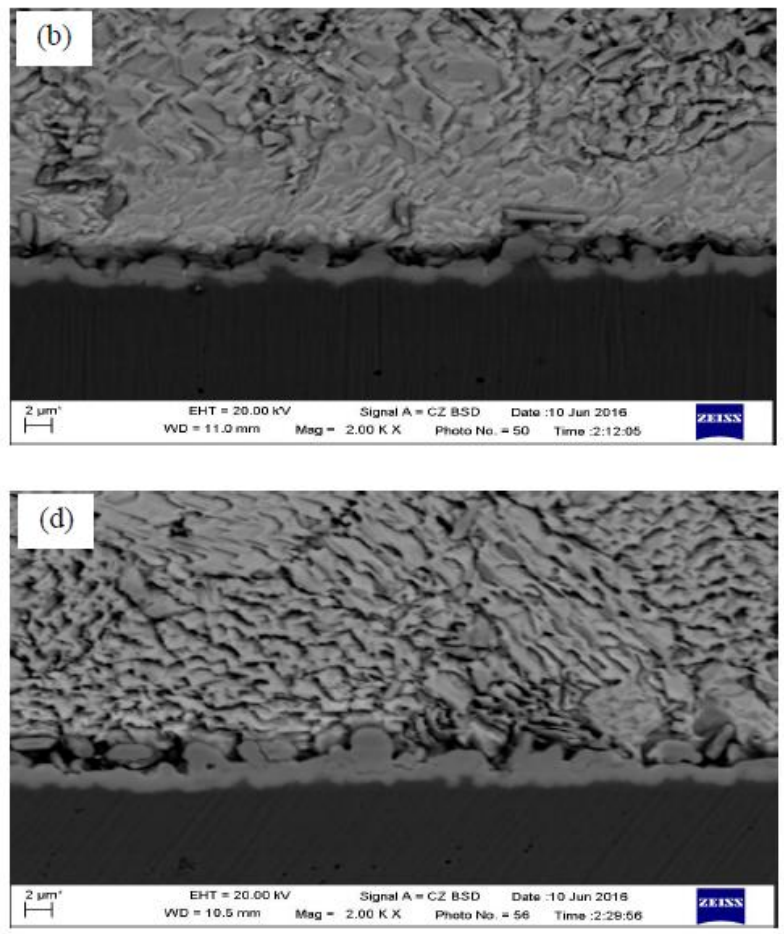

Figure 1. The BSE images of IMC layers aged at $150^{\circ} \mathrm{C}$ for: (a) 2days, (b) 4 days, (c) 6 days, (d) 8 days, and (e) 10 days. 
The reason is mainly due to the interval aging style. As well known, the growth of IMC layer follows diffusion control mechanism. At the aging stage, $\mathrm{Cu}$ atoms come from $\mathrm{Cu}$ substrate diffuse to the IMC layer, as $(\mathrm{Cu}, \mathrm{Ni})_{6} \mathrm{Sn}_{5}$ phase is thermodynamic-cally unstable, it will react with $\mathrm{Cu}$ atom to form stable phase, proceeding as $(\mathrm{Cu}, \mathrm{Ni}) 6 \mathrm{Sn} 5+$ $9 \mathrm{Cu} \rightarrow 5 \mathrm{Cu}_{3} \mathrm{Sn}+6 \mathrm{Ni}$. Unfortunately, $\mathrm{Cu}_{3} \mathrm{Sn}$ is harmful to the reliability of solder joints. It seems that the behavior of $\mathrm{Cu}_{3} \mathrm{Sn}$ during its growth is strongly dependent on the diffusion of the dominant reactive species and on the reaction pathway. If the aging time is long enough and the $\mathrm{Cu}$ substrate contains impurities, there will be some voids form in the $\mathrm{Cu}_{3} \mathrm{Sn}$ layer, which is usually called Kirkendall void. It is worth noting that the number of Kirkendall voids will increase with increasing aging time, leading to the formation of the micro-crack, which is detrimental to the reliability of solder joint.

In present study, due to the interval aging style, according to kinetics, the activation energy is not high enough to overcome the kinetic energy barrier and make the $(\mathrm{Cu}, \mathrm{Ni})_{6} \mathrm{Sn}_{5}$ phase change into $\mathrm{Cu}_{3} \mathrm{Sn}$. Hence, there is no $\mathrm{Cu}_{3} \mathrm{Sn}$ appeared and only $(\mathrm{Cu}, \mathrm{Ni})_{6} \mathrm{Sn}_{5}$ phase formed, consequently, the reliability of solder joints is improved.

According to classic kinetic theory ${ }^{[13]}$, generally, For the diffusion-controlled mechanism, the growth of intermetallic compound layer thickness after aging should follow the square root of time power law relationship that can be expressed as

$$
\mathrm{X}=\mathrm{X}_{0}+\mathrm{kt}^{1 / 2}
$$

where $\mathrm{X}$ is the IMCs layer thickness after aging, $\mathrm{X}_{0}$ is the initial thickness of IMCs layer after reflow soldering, $t$ is aging time, and $\mathrm{k}$ is a constant about growth coefficient.

Fig. 2 shows the thickness of the interfacial IMC layers as a function of square root of the aging time. It is seen that the IMC layer thickness increases almost linearly over the aging time, the thickness of IMC layer follows:

$$
\mathrm{X}=0.70+0.16 \mathrm{t}^{1 / 2}
$$

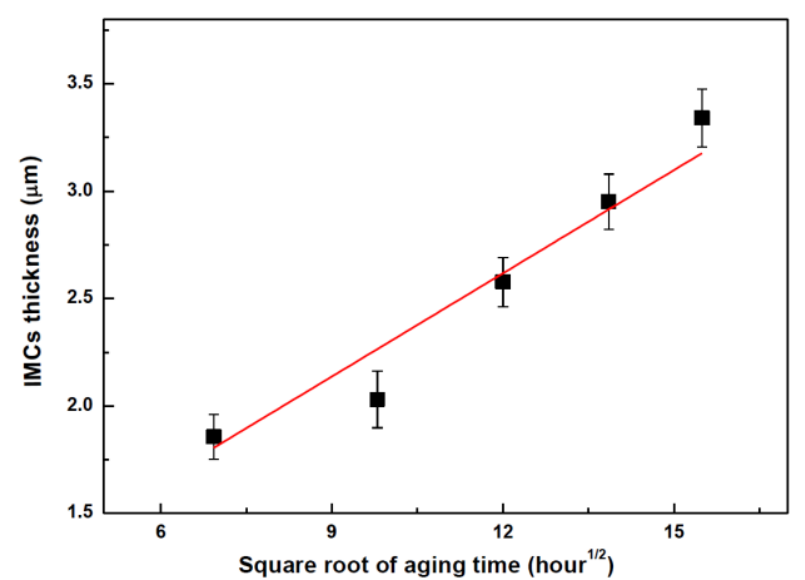

Figure 2. Interfacial IMC thickness of $\mathrm{Sn}-0.3 \mathrm{Ag}-0.7 \mathrm{Cu}-0.5 \mathrm{Bi}-\mathrm{Ni} / \mathrm{Cu}$ joints with different aging time.
From the figure, it is confirmed that the growth of interfacial IMC layers follows diffusion control mechanism. In addition, other researchers ${ }^{[14,15]}$ noticed that the interfacial IMC layers in many solder systems follow the diffusion control mechanism.

Furthermore, we can predict that the IMC layer in this study is thinner than that with continuously aging, and the growth coefficient is smaller, too. Unfortunately, we didn't study the $\mathrm{Sn}-0.3 \mathrm{Ag}-0.7 \mathrm{Cu}-0.5 \mathrm{Bi}-\mathrm{Ni}$ solder with continuously aging, thus, we will study the normal aging in the following work.

\section{CONCLUSIONS}

To simulate the real application environment of a number of electronic products, the growth of $\mathrm{Sn}-0.3 \mathrm{Ag}-0.7 \mathrm{Cu}-0.5 \mathrm{Bi}-\mathrm{Ni} / \mathrm{Cu}$ solder joints with low content of $\mathrm{Ag}$ was investigated during interval solid-state aging, It shows that the thickness of IMC $(\mathrm{Cu}, \mathrm{Ni})_{6} \mathrm{Sn}_{5}$ layer increases linearly with the square root of aging time, and the growth behavior of IMC $\left(\mathrm{Cu}, \mathrm{Ni}_{6}\right)_{6} \mathrm{Sn}_{5}$ layer follows $\mathrm{X}=0.70+0.16 \mathrm{t}^{1 / 2}$. It demonstrates that growth the IMCs layers both follow diffusion control mechanism no matter in continuous aging mode or in interval aging mode. Further, it is illustrated that only IMC $(\mathrm{Cu}, \mathrm{Ni})_{6} \mathrm{Sn}_{5}$ layer forms, and there is still no IMC $\mathrm{Cu}_{3} \mathrm{Sn}$ layer appear whatever the increasing aging time. This is different from the IMCs formation during continuously aging. This phenomenon is probably attributing to the interval aging mode. From kinetical analysis, it is concluded that due to the interval aging, the activation energy is not high enough to overcome the kinetic energy barrier and make the $(\mathrm{Cu}, \mathrm{Ni})_{6} \mathrm{Sn}_{5}$ phase change into $\mathrm{Cu}_{3} \mathrm{Sn}$. Hence, the reliability of $\mathrm{Sn}-0.3 \mathrm{Ag}-0.7 \mathrm{Cu}-0.5 \mathrm{Bi}-\mathrm{Ni} / \mathrm{Cu}$ solder joints can be improved.

\section{ACKNOWLEDGMENTS}

The authors would like to acknowledge the financial support provided by National Natural Science Foundation of China (NSFC) under grant Nos. 51604012 and 51575004 , Foundation of Beijing outstanding talent training under grant (2) No.2014000020124G010, and Natural Science Foundation of Beijing (NSFB) under grant No.3162010.

\section{REFERENCES}

[1] W. X. Chen, S. B. Xue, H. Wang, J. X. Wang, Z.J. Han and L. L. Gao, "Effects of $\mathrm{Ag}$ on microstructures, wettabilities of $\mathrm{Sn}-9 \mathrm{Zn}-\mathrm{XAg}$ solders as well as mechanical properties of soldered joints,"J. Mater. Sci: Mater. Electron., vol. 21, pp.461-467, 2010.

[2] A. A. El-Daly, A. M. El-Taher and S. Gouda, "Novel Bi-containing Sn-1.5Ag-0.7Cu lead-free solder alloy with further enhanced thermal property and strength for mobile products," Mater. Design, vol. 65, pp. 796-805, 2015

[3] E. Çadırlı, U. Böyük, H. Kaya and N. Maraşl, "Determination of mechanical, electrical and thermal properties of the Sn-Bi-Zn ternary alloy,'J. Non-Cryst.Solids, vol.357, pp. 2876-2881, 2011.

[4] J. W. Yoon, J. H. Bang, C. W. Lee and S. B. Jung, "Interfacial reaction and intermetallic compound formation of Sn-1Ag/ENIG and Sn-1Ag/ ENEPIG solder joints," J. Alloy. Comp., vol. 627, pp. 76-280, 2015.

[5] C. Y. Liu, M. H. Hon, M. C. Wang, Y. R. Chen, K. M. Chang and W. $\mathrm{L}$. $\mathrm{Li}$, "Effects of aging time on the mechanical properties of Sn-9Zn-1.5Ag-xBi lead-free solder alloys,"J. Alloy. Comp., vol. 582, 
pp.229-235, 2014.

[6] A. A. El-Daly, A. Z. Mohamad, A. Fawzy and A.M. El-taher, "Creep behavior of nearperitectic Sn-5Sb solders containing small amount of $\mathrm{Ag}$ and Cu," Mate. Sci. Eng., vol. 528 A, pp.1055-1062, 2011.

[7] A. A. El-Daly and A. E. Hammad, "Enhancement of creep resistance and thermal behavior of eutectic Sn-Cu lead-free solder alloy by $\mathrm{Ag}$ and In-additions," Mater. Design, vol.40, pp.292-298, 2012.

[8] A. A. El-Daly, A.M. El-taher and T. R. Dalloul, "Enhanced ductility and mechanical strength of Ni-doped $\mathrm{Sn}-3.0 \mathrm{Ag}-0.5 \mathrm{Cu}$ lead-free solders," Mater. Design, vol. 55, pp. 309-318, 2014.

[9] H. L. Li, R. An, C. Q. Wang, Y. H. Tian and Z. Jiang, "Effect of $\mathrm{Cu}$ grain size on the voiding propensity at the interface of $\mathrm{SnAgCu} / \mathrm{Cu}$ solder joints," Mater. Letters, vol. 144, pp.97-99, 2015.

[10] L. Y. Xu, L. X. Wang, H. Y. Jing, X. D. Liu, J. Wei and Y. D. Han, "Effects of graphene nanosheets on interfacial reaction of $\mathrm{Sn}-\mathrm{Ag}-\mathrm{Cu}$ solder joints," J. Alloy. Comp., vol. 650, pp. 475-481, 2015.

[11] H. J. Ji, Y. F. Qiao and M. Y. Li, "Rapid formation of intermetallic joints through ultrasonic-assisted die bonding with $\mathrm{Sn}-0.7 \mathrm{Cu}$ solder for high temperature packaging application," Script. Mater., vol. 110, pp. 19-23, 2016.

[12] H.R. Kotadia, P. D. Howes and S. H. Mannan, "A review: On the development of low melting temperature $\mathrm{Pb}$-free solders," Micro. Reliab., vol. 54, pp.1253-12732014.

[13] P. L. Tu, Y. C. Chan, K. C. Hung and J. K. L. Lai, "Growth kinetics of intermetallic compounds in chip scale package solder joint," Script. Mater., vol.44, pp. 317-323, 2001.

[14] X.W. Hu, Y. L. Li and Z. X. Min, "Interfacial reaction and IMC growth between Bi-containing $\mathrm{Sn} 0.7 \mathrm{Cu}$ solders and $\mathrm{Cu}$ substrate during soldering and aging," J. Alloy. Comp., vol. 582, pp. 341-347, 2014.

[15] H. Nishikawa and N. Iwata, "Formation and growth of intermetallic compound layers at the interface during laser soldering using $\mathrm{Sn}-\mathrm{Ag}-\mathrm{Cu}$ solder on a $\mathrm{Cu}$ pad," J. Mater. Pro. Tech., vol. 215, pp. 6-11, 2015. 